\title{
IMPLEMENTASI SISTEM INFORMASI GEOGRAFIS LAYANAN PUBLIK LINGKUP KOTA PAREPARE BERBASIS WEB
}

\author{
Neneng Awaliah'1, Nuraida Latif ${ }^{2}$, Markani ${ }^{3}$ \\ Sistem Informasi STMIK AKBA ${ }^{1}$, Teknik Informatika STMIK AKBA ${ }^{2}$, Sistem Informasi STMIK AKBA ${ }^{3}$ \\ neneng@akba.ac.id ${ }^{1}$, nuraida@akba.ac.id², markani@akba.ac.id ${ }^{3}$
}

\begin{abstract}
ABSTRAK
Kota Parepare pada saat ini terus meningkatkan serta mengembangkan pelayanan disegala bidang khususnya dibidang pelayanan kesehatan. Namun banyak kendala yang dialami, salah satunya adalah melakukan sosialisasi layanan-layanan kesehatan yang ada di Kota Parepare. Sosalisasi berupa informasi letak dan informasi suatu layanan kesehatan yang ada disekitar tempat tinggal mulai dari rumah sakit, Apotek 24 jam, Puskesmas, Klinik, Dokter umum/spesialis, dan Alternatif. Untuk itu perlu dirancang suatu sistem informasi geografis (SIG) yang dapat mengetahui letak dan fasilitas layanan kesehatan yang ada di Kota Parepare yang nantinya dapat mempermudah masyarakat. Selain itu, SIG juga dikembangkan sebagai media analisa perencanaan dalam proses pembangunan peningkatan sarana dan prasarana, sehingga pengolahan data atau informasi yang kurang efektif menjadi lebih efektif serta mampu memberikan informasi yang tepat kepada masyarakat. Sistem ini juga dapat bermanfaat untuk menunjang pengambilan keputusan dan pemantauan pengendalian pemerintah daerah.
\end{abstract}

Kata Kunci: Sistem Informasi Geografis, Layanan Kesehatan, Pare-pare.

\begin{abstract}
Currently, the City of Parepare continues to improve and develop services in all fields, especially in the field of health services. However, there are many obstacles, one of which is disseminating health services in the City of Parepare. Socialization in the form of information on the location and information of a health service that is around the residence starting from the hospital, 24 hour pharmacy, health center, clinic, general practitioner / specialist, and alternatives. For this reason, it is necessary to design a geographic information system (GIS) that can determine the location and health service facilities in the City of Parepare which will make it easier for the community. In addition, GIS is also developed as a planning analysis medium in the development process of improving facilities and infrastructure, so that ineffective data or information processing becomes more effective and able to provide accurate information to the public. This system can also be useful to support decision making and monitoring of local government control.
\end{abstract}

Keywords: Geographic Information System, Health Services, Pare-pare. 


\section{PENDAHULUAN}

Kota Parepare pada saat ini terus meningkatkan serta mengembangkan pelayanan disegala bidang khususnya dibidang pelayanan kesehatan. Namun banyak kendala yang dialami, salah satunya adalah melakukan sosialisasi layanan-layanan kesehatan yang ada di Kota Parepare.

Sebagai contoh masyarakat ingin mencari letak dan informasi suatu layanan kesehatan yang ada disekitar tempat tinggal mulai dari RS(Rumah Sakit), Apotek 24 jam, Puskesmas, Klinik, Dokter umum/spesialis, dan Alternatif. Namun masyarakat tidak mengetahui bagaimana cara mendapatkan informasi tersebut. Untuk itu perlu dirancang suatu sistem informasi geografis yang dapat mengetahui letak dan fasilitas layanan kesehatan yang ada di Kota Parepare yang nantinya dapat mempermudah masyarakat.

Teknologi informasi dalam hal ini merupakan alat bantu yang paling tepat digunakan untuk memberikan hasil maksimal. Pembuatan sistem informasi geografis (SIG) berbasis web ini dapat membantu mengetahui letak layanan kesehatan masyarakat yang ada di Kota Parepare selain pada kasus yang lain juga dapat memberikan informasi kepada masyarakat tentang prediksi cuaca, keselamatan dan keamanan, mudah, cepat dan efektif [1] serta SIG dapat digunakan untuk Pemetaan kondisi pendidikan dilakukan menggunakan metode Self Organizing Maps [2]. Sementara itu web merupakan salah satu sumber informasi yang banyak dipakai untuk sarana promosi bagi sekolah dan pusat kesehatan masyarakat yang ada di suatu daerah.

SIG juga berguna sebagai media analisa perencanaan dalam proses pembangunan peningkatan sarana dan prasarana, karena SIG mempunyai kemampuan analisis keruangan (spatial analysis) maupun waktu (temporal analysis), sehingga pengolahan data atau informasi yang kurang efektif menjadi lebih efektif serta mampu memberikan informasi yang tepat kepada masyarakat. SIG akan menampilkan data secara real time atau menampilkan kembali (playback) data - data yang lalu yang akan diberi simbol dan warna tertentu berdasarkan atribut, waktu dan posisinya [3]. Sistem ini juga dapat bermanfaat untuk menunjang pengambilan keputusan dan pemantauan pengendalian pemerintah daerah.

\section{TINJAUN PUSTAKA}

\subsection{Sistem Informasi Geografis (SIG)}

Sistem Informasi Geografis (SIG) merupakan suatu sistem (berbasiskan komputer) yang digunakan untuk menyimpan dan memanipulasi informasi-informasi geografis. SIG dirancang untuk mengumpulkan, menyimpan, dan menganalisis objek-objek dan fenomena-fenomena dimana lokasi geografis merupakan karakteristik yang penting atau kritis untuk dianalisis. Dengan demikian, SIG merupakan sistem komputer yang memiliki empat kemampuan berikut dalam menangani data yang bereferensi geografis : (a) masukan, (b) keluaran, (c) manajemen data (penyimpanan dan pemanggilan data), (d) analisis dan manipulasi data. (Eddy Prahasta, Tutorial ArcView, [4]

Penggunaan Sistem Informasi Geografis (SIG) meningkat tajam sejak tahun 1980-an. Peningkatan pemakaian sistem ini terjadi di kalangan pemerintah, militer, akademis, atau bisnis terutama di negara-negara maju. Perkembangan teknologi digital sangat besar peranannya dalam perkembangan penggunaan SIG dalam berbagai bidang. Hal ini dikarenakan teknologi SIG banyak mendasarkan pada teknologi digital ini sebagai alat analisis.

Teknologi GIS (Georaphic Information System) telah berkembang pesat. Saat ini telah dikenal istilah-istilah Desktop GIS, WebGIS, dan Database Spatial yang merupakan wujud perkembangan teknologi Sistem Informasi Geografis, untuk mengakomodir kebutuhan solusi atas berbagai permasalahan yang hanya dapat dijawab dengan teknologi GIS ini. (Hatma, "WebgGIS dengan MapServer - MapLab - Chameleon PostGIS", h.1

\section{http://www.hatma.info/download/gis/webgis/Tutorial} _webGIS.pdf (03 Juni 2010)

Secara teknis SIG mengorganisasikan dan memanfaatkan data dari peta digital yang tersimpan dalam basis data. Dalam SIG, dunia nyata dijabarkan dalam data peta digital yang menggambarkan posisi dari ruang (space) dan klasifikasi, atribut data, dan hubungan antar item data. Kerincian data dalam SIG ditentukan oleh besarnya satuan pemetaan terkecil yang dihimpun dalam basis data. Dalam bahasa pemetaan kerincian itu tergantung dari skala peta dan dasar acuan geografis yang disebut sebagai peta dasar.

\subsection{Web-based GIS}

Web-based GIS merupakan aplikasi SIG yang dibuat dengan basis jaringan internet dan dibangun atas dasar konsep arsitektur client-server. Dengan konsep arsitektur ini, beberapa program aplikasi dapat bertindak sebagai server (penyedia informasi), sementara program aplikasi yang lain dapat bertindak sebagai client (penerima informasi). Walaupun demikian, arsitektur web-based ini tidak membatasi koneksi satu ke satu, tetapi sebuah client dapat mengakses banyak server yang berbeda, sementara server-nya dapat pula diakses oleh banyak client yang berbeda. Aplikasi SIG yang berjalan di internet seperti ini hanya menampilkan peta-peta digital denga simbol-simbol, legenda berwarna, dan tabel atribut, menyediakan beberapa fungsi manipulasi tampilan : 
zoom-in, zoom-out, dan pan, serta dapat menjalankan fungsi query sederhana tanpa dapat berhubungan langsung dengan GIS-engine-nyakarena terlebih dahulu harus berhubungan dengan server web dan server aplikasinya.

\subsection{Manajemen Data SIG}

Aplikasi SIG berbasis web tidak dapat dipisahkan dengan sistem manajemen basis data yang sudah melekat secara inherent di dalamnnya. Oleh karena itu progres pada bidang ini juga merupakan suatu kemajuan pada aplikasi SIG itu sendiri. Dengan demikian dapat dipastikan bahwa teknologi aplikasi SIG berbasis web didukung oleh konsep dan teknologi di bidang sistem manajemen basis data.

Aplikasi SIG berbasis internet tidak memiliki tipe data spasial khusus yang baru atau tersendiri, melainkan menggunakan yang sudah ada dapat juga terbaca oleh desktop-based GIS seperti : coverage ArcInfo, shapefile ArcView, table dan MIF MapInfo, DXF/DWG AutoCad, GeoDatabase ArcGIS [5] dan google maps yang memiliki API Key di embedded kedalam pemprograman untuk memaksimalkan kinerja dari google maps [6]. Setiap format ini memiliki spesifikasi (requirements) dan keistemewaan tersendiri. Dengan demikian, segala progres pada pengembangan tipe data spasial juga akan memberikan impact pada aplikasi SIG berbasis internet karena format-formatnya yang perlu diakomodasi, apalagi jika format tersebut dijadikan sebagai sebuah standard yang berlaku di suatu komunitas [7].

\section{METODE YANG DIUSULKAN}

Tahap pengembangan pada sistem SIG menggunakan sistem RAD (Rapid Application Development) ini terdiri dari beberapa aktifitas yang tentunya sesuai dengan tahapan yang telah dijabarkan pada alur proses pengembangan sistem

Tahap-tahan yang dilakukan sebagai berikut:

\subsection{Tahap Perencanaan Syarat-Syarat}

Menggabungkan laporan hasil metode studi lapangan berupa kebijakan pemakai menjadi spesifikasi yang terstruktur dengan menggunakan pemodelan yang berfungsi untuk mengetahui kebutuhan pemakai, kesalahan-kesalahan dalam sistem lama seperti sistem yang masih manual sehingga data menjadi tidak teratur. Dari analisis sistem tersebut dapat ditetapkan tujuan perancangan, pengajuan usulan yang dapat diterima.

\subsection{Perancangan Sistem (Workshop Design)}

Pada tahap ini peneliti mendesain sistem yang diusulkan agar dapat berjalan dengan lebih baik dan diharapkan dapat mengatasi masalah-masalah yang ada.

Pada tahap ini alat yang digunakan sama dengan tahap analisis system yaitu UML (Unified Modelling Language), alasannya adalah untuk lebih memahami langkah awal membangun sistem secara fisik. Berikut adalah Diagram UML-nya :

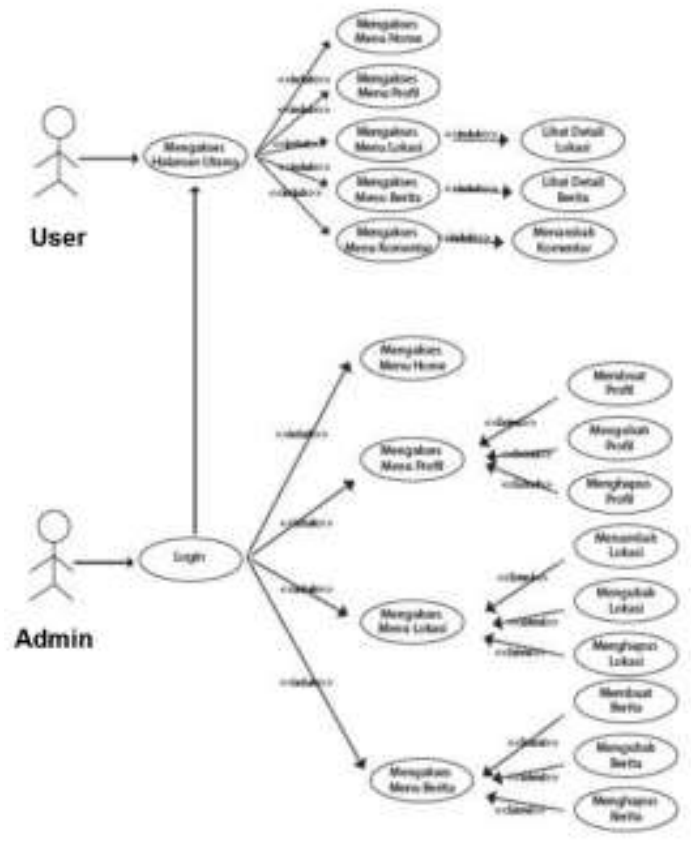

Gambar 1. Use Case System

\subsection{Tahap perancangan basis data}

Pada tahap ini dilakukan dengan Class Diagram yang menggambarkan hubungan antar entity yang ada pada Use Case Diagram dan spesifikasi tabel.

\subsection{Tahap perancangan Input-Output}

Pada tahan ini dilakukan dengan membuat rancangan layar tampilan. Setelah rancangan layar tampilan terbentuk maka dilakukan tahap konstruksi. Berikut adalah rancangan interface-nya :

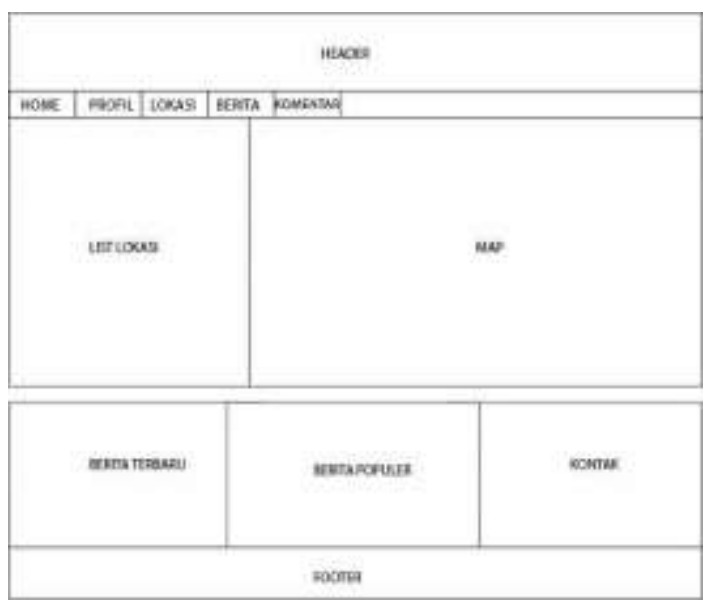

Gambar 2. Desain User Interface Halaman Home 


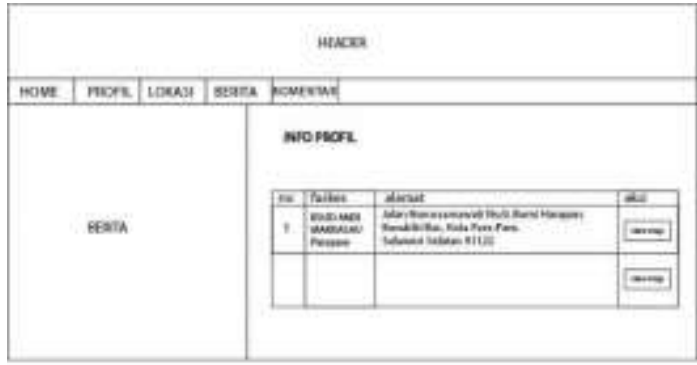

\section{poots}

Gambar 3. Desain User Interface Halaman Pofil
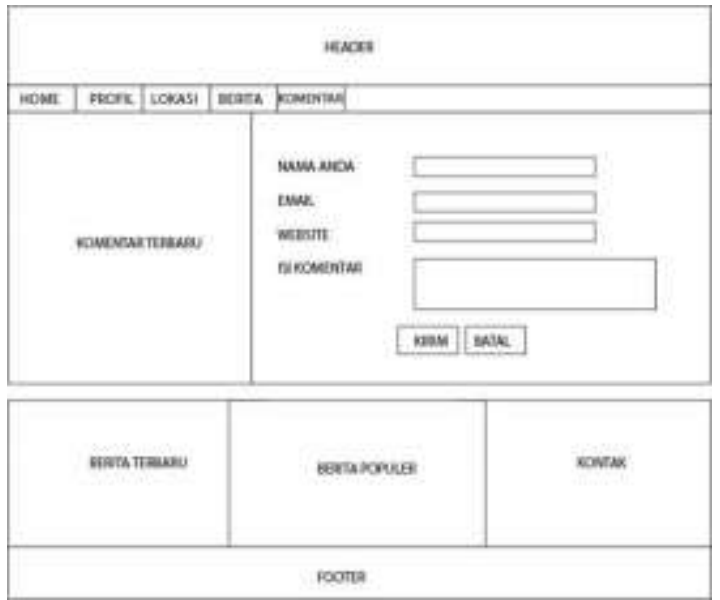

Gambar 4. Desain User Interface Halaman Komentar

\subsection{Tahap Implementasi Sistem}

Setelah melakukan analisis sistem dan perancangan sistem secara rinci, maka tiba saatnya sistem untuk diimplementasikan. Pada tahap ini terdapat banyak aktivitas yang dilakukan [8].

\subsection{Tahap Pengujian}

Pada tahap ini dilakukan uji coba terhadap sistem yang baru agar dapat digunakan tanpa menemukan kendala-kendala apapun. Adapun ujicoba yang akan dilakukan dengan menggunakan metode black box testing.

\section{HASIL DAN PEMBAHASAN}

Pada bagian ini akan di bahas mengenai hasil dari Tampilan program yang telah di buat.

A. Halaman Admin

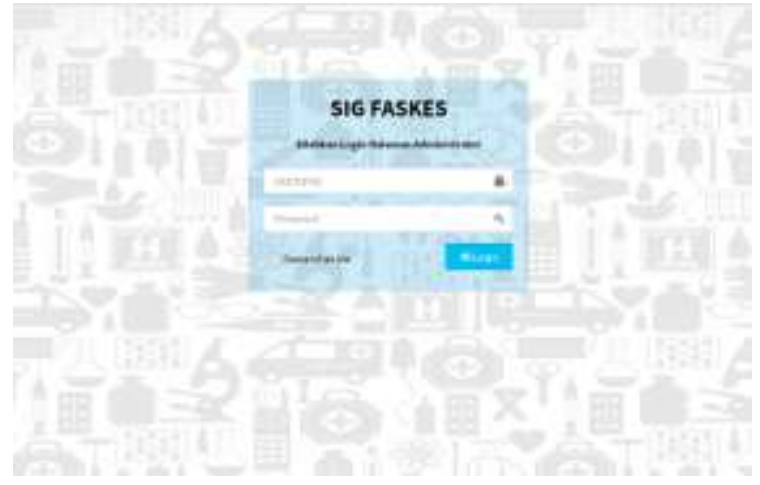

Gambar 5. Halaman Login Sistem

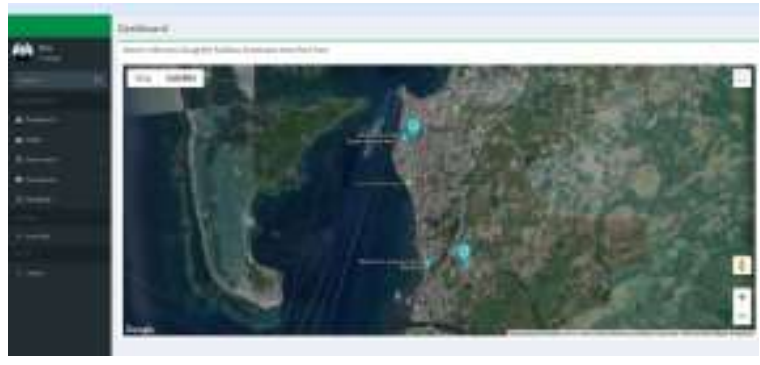

Gambar 6. Halaman Sistem Informasi Geografis

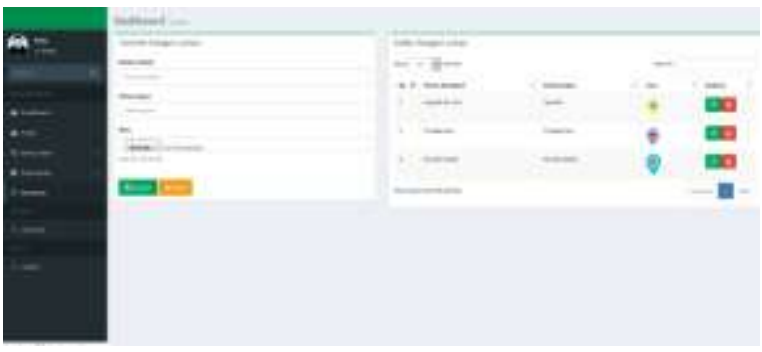

Gambar 7. Halaman Data Sistem

B. Halaman User

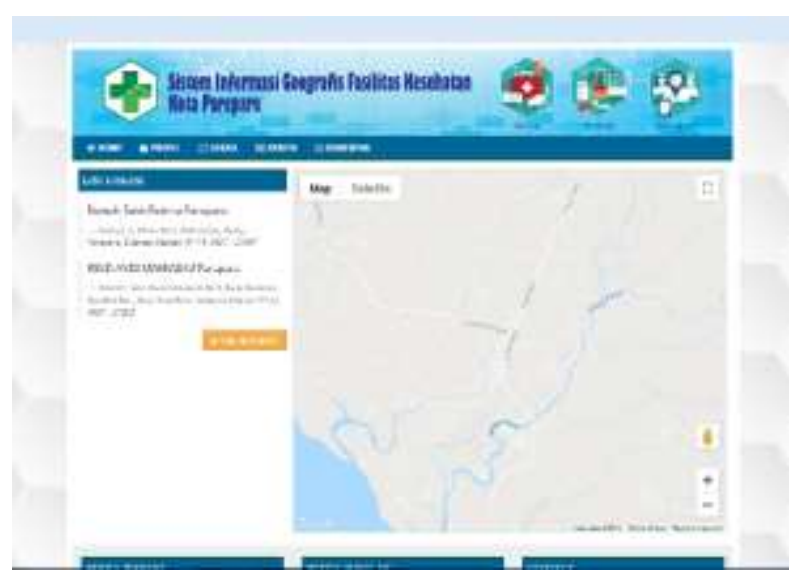

Gambar 8. Halaman Pengunjung 
Halaman List Lokasi.

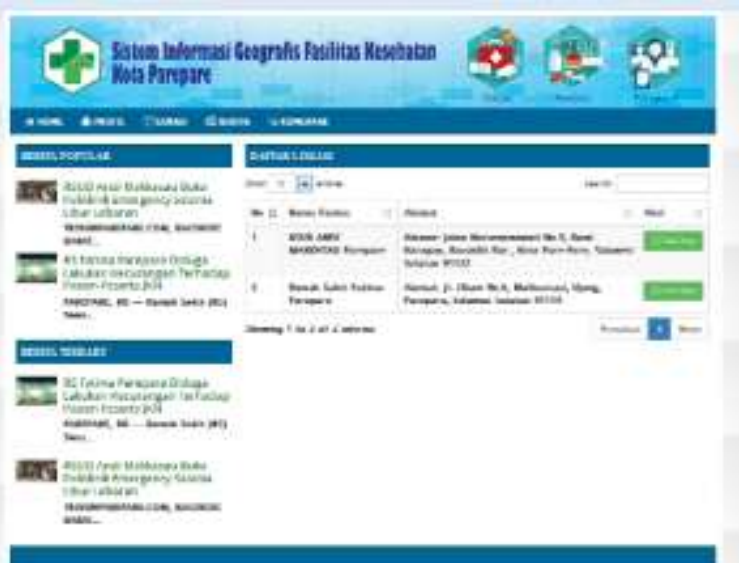

Gambar 9. Tampilan Halaman Admin setelah Halaman detail Lokasi

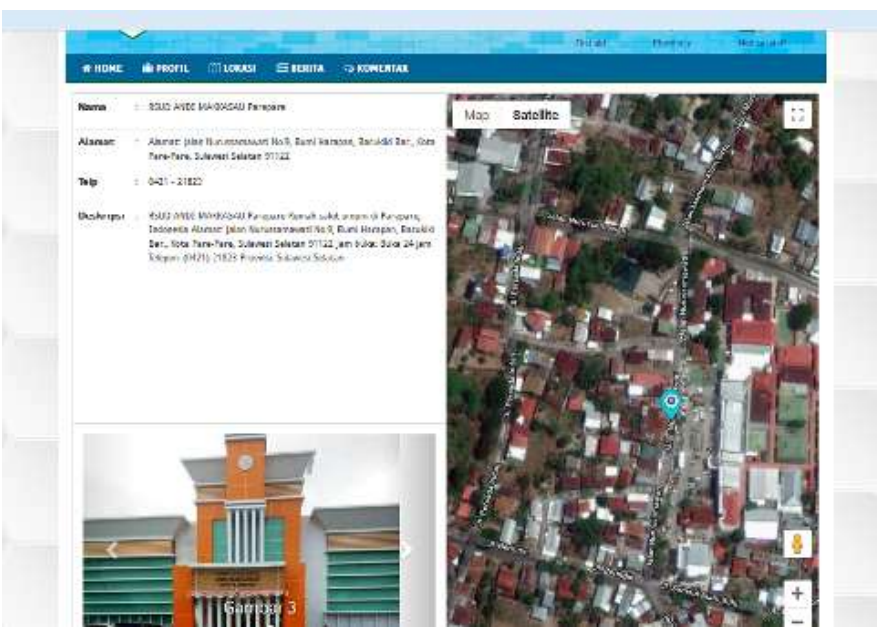

Gambar 10. Menu Peta Lokasi

\section{KESIMPULAN}

Sistem Informasi Geografis Layanan Kesehatan berbasis web dapat diakses oleh pengguna dimana saja melalui media internet dengan memberikan informasi geografis lokasi pelayanan kesehatan berupa rumah sakit, puskesmas, dan apotek di Kota Parepare. Hasil pengujian sistem dengan metode white box untuk pengujian logik dan metode black box untuk pengujian interface. Menunjukkan efektifitas sistem dan aksesibilitas yang baik. Penelitian selanjutnya dapat dilakukan dengan melengkapi data dan informasi yang lebih banyak dan lebih akurat. Serta dengan metode komputasi yang lebih baik

\section{DAFTAR PUSTAKA}

[1] Fatkhudin, A. (2019). Sistem Informasi Geografis Wisata Gunung Di Pekalongan Berbasis Android. Jurnal Ilmiah Ilmu Komputer Fakultas Ilmu Komputer Universitas Al Asyariah Mandar, 5(1), 13-18.

[2] Syarli, S., \& Qashlim, A. (2017). Sistem Informasi Geografis Kawasan Bencana Alam Kabupaten Polewali Mandar Dengan Google Maps. Jurnal Ilmiah Ilmu Komputer Fakultas Ilmu Komputer Universitas Al Asyariah Mandar, 3(2), 21-27.

[3] Masrianto, Harianto, Kahfi, A., \& Sarjan, M. (2020). Implementasi Peta Digital untuk Smart Village (Studi Kasus Desa Tammangalle, Polewali Mandar). Jurnal Ilmiah Ilmu Komputer Fakultas Ilmu Komputer Universitas Al Asyariah Mandar, 6(1), 13-18

[4] Prahasta, Eddy. 2002. Sistem Informasi Geografis: Konsep-Konsep Dasar Informasi Goegrafis. Bandung: Informatika Bandung.

[5] Kumar, A., dan Diwakar, P. S. (2015), "Web GIS based Land Information System for Bhopal City using open Source Software and Libraries", International Journal of Science, Engineering and Technology Research (IJSETR), Vol. 4, Issue 1, hal. $154-157$

[6] Syarli, S., \& Qashlim, A. (2017). Pemetaan Pemerataan Pendidikan Menggunakan Self Organizing Maps (SOM) Terintegrasi Sistem Informasi Geografis. Jurnal Ilmiah Ilmu Komputer Fakultas Ilmu Komputer Universitas Al Asyariah Mandar, 3(2), 27-34.

[7] Abidin, H. Z. (2007), Penentuan Posisi dengan GPS dan Aplikasinya, Cetakan Ketiga, PT. Pradnya Parami, bandung

[8] Purwatiningtyas dan Erniyati, Sri. 2011. "Peranan Teknologi Informasi dalam Rangka Peningkatan Pelayanan Publik". Jurnal Teknologi Informasi DINAMIKA Volume 16, No.1, Juli 2011: 150. 